\title{
AMERICAN PRESIDENTS AND POLITICIANS IN RHYMING SLANG
}

\author{
K. Stepanyan \\ Moscow State Institute of International Relations (University), \\ 76, prospect Vernadskogo, Moscow 119454, Russia

\section{Y. Gorshunov} \\ Bashkir State University at Birsk, \\ 10, Internacionalnaya st., Birsk, 452453, Russia

\section{E. Gorshunova} \\ Russian Academy of National Economy and Public Administration \\ 82/1 prospect Vernadskogo, Moscow 119571, Russia
}

\begin{abstract}
The article is aimed at identifying onomastic rhymes as part of rhyming slang and analyzing them from a socio-cultural perspective. They are built on the names of American celebrities from the world of politics and social activities and believed to be fixers of cultural and historical items that are of certain value from the point of view of culture-oriented linguistics, cross-cultural communication and the general study of culture. The research methods applied are determined by the purpose and objectives of the research and include a descriptive and a linguistic ones, the latter comprising context and definitional analysis, and also semantic interpretation.

The rhymes are based on the names that have been widely represented in the media from the middle of the twentieth century to the present day, thus forming part of the modern cultural collective memory of the carriers of the English-speaking culture. The noted tendency of preferential creation of new rhymes, exploiting precedent onyms, became dominant in the development of rhyming slang at the turn of the century. The authors come to the conclusion that the rhymes illustrating the world of high politics have been added to the well-mastered and familiar onomastic rhymes, built on the names of celebrities from the world of cinema, pop music, popular culture and sports. The article brings to light the rhymes that have not yet been recorded in authoritative slang dictionaries.

The research results can be of interest to the specialists working on the topics of intercultural communication, linguistic and cultural studies, cultural linguistics, political linguistics, euphemization, contrastive linguistics of the English and Russian languages.
\end{abstract}

Key Words: rhyming slang, precedent name, cultural memory, English-speaking culture 


\title{
АМЕРИКАНСКИЕ ПРЕЗИДЕНТЫ И ПОЛИТИЧЕСКИЕ ДЕЯТЕЛИ В РИФМОВАННОМ СЛЕНГЕ
}

\author{
К.А. Степанян \\ Московский государственный институт международных отношений (университет) МИД России, \\ 119454, г. Москва, проспект Вернадского, 76
}

\section{Ю.В. Горшунов}

Башкирский государственный университет (Бирский филиал) г. Бирск, ул. Интернациональная, 10, 452453, Россия

\section{Е. Ю. Горшунова}

Российская академия народного хозяйства и госслужбы, 119571, г. Москва, проспект Вернадского 82, стр.1

\begin{abstract}
Аннотация. Статья нацелена на выявление ономастических рифм в составе рифмованного сленга и проведение их соииокультурного анализа. Ономастические рифмы построены на именах видных политических, государственных и общественных деятелей США и рассматриваются как фиксаторы культурно-исторических реалий, обладающих лингвострановедческой и лингвокультурологчческой иенностью. Для проведения исследования использовались следующие методь: описательный и тингвистический метод, включающий контекстньй, дефиниционный анализ и метод семантической интерпретации.

В фокусе внимания авторов оказались основанные на именах рифмы, широко представленные в СМИ начиная с середины ХХ века вплоть до наших дней и входящие, таким образом, в современную культурную коллективную память носителей англоговорящей культурь. Отмеченная тендениия предпочтительного создания новых рифм, эксплуатирующих прецедентные онимы, стала доминирующей в развитии рифмованного сленга на рубеже столетий. Авторы приходят $\kappa$ выводу, что к хорошо освоенным и привычным ономастическим рибмам, построенным на именах знаменитостей из мира кино, поп-музыки, массовой культуры и спорта, добавились рифмы, иллюстрирующие мир высокой политики. В статье отмечены рифмь, ещзё не зафиксированные в авторитетных словарях сленга. Результаты исследования могут быть практически полезными и интересньми для специалистов, разрабатьвающих темь межкультурной коммуникаиии, лингвострановедения, лингвокультурологии, политической тингвистики, эвфемии, контрастивной лингвистики английского и русского языков.
\end{abstract}

Ключевые слова: рифмованный сленг, прецедентное имя, культурная память, англоговорящая культура

\section{ВВЕДЕНИЕ}

татья нацелена на выявление ономастических рифм в составе рифмованного сленга, построенных на именах американских знаменитостей из мира политики и общественной деятельности, чтобы дать им надлежащую социокультурную характеристику как фиксаторам культурно-исторических реалий, обладающих лингвострановедческой и лингвокультурологической ценностью. 
О рифмованном сленге имеется богатая литература, включающая словари, монографии, диссертационные исследования, статьи. Рифмованный сленг - перспективная и интенсивно разрабатываемая тема в современной англоязычной лингвистике. Современных исследователей интересуют такие проблемы рифмованного сленга, как территориальная и социальная дифференциация, его эволюция, новые тенденции в развитии, выполняемые функции (например, эвфемистическая, игровая) и др. Новый вектор исследования - лингвострановедческая перспектива [3]. Объёмная библиография представлена в монографии [5].

Суть рифмованного сленга заключается в том, что для общения используется код, заменяющий обычное слово какой-либо фразой, которая рифмуется с этим словом, например, stairs $\triangleright$ apples and pears; believe $\triangleright$ Adam and Eve; beers $\triangleright$ Britney Spears. Таким образом, apples and pears = stairs; Adam and Eve = believe; Britney Spears = beers. Часто в среде истинных носителей кокни одно из слов хорошо известной рифмы (как правило, второе) вообще опускается, что делает сленг ещё более трудным для восприятия: china $\triangleleft$ china plate = mate; bone $\triangleleft$ dog and bone = phone; plates $\triangleleft$ plates of meat $=$ feet.

Для решения заявленной нами цели методом сплошной выборки были отобраны рифмы, эксплуатирующие имена исторических и современных государственных и политических деятелей США, из ряда словарей сленга и рифмованного сленга [9], [10], [11], [12], [15] и других источников. Прежде всего, это имена президентов, которые оставили заметный след в истории США. В список «зарифмованных» президентов, получивших «прописку» в рифмованном сленге, вошли имена Авраама Линкольна, Дуайта Эйзенхауэра, Джорджа Буша, Барака Обамы и Дональда Трампа, причём последний «засветился» в рифмованном сленге ещё до своего президентства, когда был известен как глава фирмы The Trump Organization и организатор конкурсов красоты the Miss USA и Miss Universe, а также известных американских политиков наших дней.

В статье мы продолжаем развивать тему, затронутую в работах [1], [8]. Анализ ономастических рифм свидетельствует о том, что во многих случаях рифмованный сленг основан на использовании имён литературных, фольклорных и мифологических персонажей [1], исторических и современных государственных и политических деятелей [8], [2], известных спортсменов [4], популярных музыкантов, поп-идолов, киноактёров и т.д. Тенденция предпочтительного использования модели образования новых рифм, основанных на эксплуатации имён широко известных, модных или популярных личностей, стала определяющей в развитии рифмованного сленга на рубеже столетий.

Как выяснилось, создатели рифмованного сленга не всегда обходятся благосклонно или почтительно с именами политиков, нередко рифмуя их с референтами, обозначающими в некоторых случаях нечто неприятное [См., например, 12, с. 38]. Так, имя 16-го президента США Авраама Линкольна, главная заслуга которого - отмена рабства [6, с. 662], [14, с. 765] рифмуется со словом stinking, имеющим значения foul-smelling; disgusting, contemptible, very bad or unpleasant (зловонный, вонючий; отвратительный, противный, ужасный): Abraham Lincoln/Abie Lincoln = stinking, как в примерах: There's a dead cat in the garden and it's Abraham Lincoln! Your plates are Abraham Lincoln! (plates $\triangleleft$ plates of meet $=$ feet). Согласно общепринятой точке зрения и социальным опросам, Линкольн по-прежнему остаётся одним из лучших и самых любимых президентов Америки, хотя во время президентства он подвергался суровой критике. Национальный герой американского народа безусловно заслуживает более комплиментарных рифм!

Рифма Eisenhower = shower основана на имени 34-го президента Америки генерала Дуайта Дэвида Эйзенхауэра, который был президентом два срока с 1953 по 1961 гг. Генерал Эйзенхауэр занимает особое и очень важное место в истории Второй мировой войны: с поразительной скоростью он превращается из малоизвестного штабного офицера в одного из ведущих полководцев [6, c. 1239], главнокомандующего вооруженными силами США в Европе и командующего вооружёнными силами союзников. Он пользовался необычайной популярностью, и потому ему советовали заняться политикой. Выйдя в отставку в 1952 году, Эйзенхауэр выдвинул свою кандидатуру на президентских выборах и победил с большим преимуществом [6, с. 1239]. Став президентом, Эйзенхауэр отстаивал интересы большого бизнеса у себя на родине. Во внешней политике он был 
апологетом Холодной войны [7, с. 1135]. В США широко распространено прозвище Эйзенхауэра Ike [14, с. 420]. Рифма Eisenhower = shower интересна тем, что она однословна, что не типично для рифмованного сленга. В основном, рифмы по своей структуре являются двухкомпонентными образованиями. Феномен и суть рифмованного сленга, как мы отметили выше, заключается в замене обычного слова или устойчивого словосочетания рифмующимся с ним выражением (как правило, двухкомпонентным), которое в дальнейшем может подвергнуться сокращению и потерять рифмующуюся часть, например, Ruby Murray = curry (в основу положено имя известной ирландской певицы Руби Мюррэй, которая была одной из самых популярных певиц на Британских островах в 1950-х гг.). Ruby Murray/Murry $\triangleright$ ruby: Let's go for $\boldsymbol{a} \boldsymbol{r u b y}=$ Let's go for a curry (Давайте съедим карри). Когда двучленная рифма подвергается сокращению, опускается, как правило, последнее слово. Обычно в речи в подходящем контексте используются сокращённые варианты. Например, абсолютно естественно звучит усечённое butcher's, производное от butcher's hook = look и minces, производное от mince pies = eyes: Let's take a butcher's at your black minces [15, с. 45], что в переводе на нормальный язык означает Let's have a look at your black eyes [15, c. 47].

Джордж Буш-младший был 43-м президентом США в 2001-2009 годах. Он запечатлён в рифмованном сленге рифмой George Bush = mush (face), редуцируемой в разговорной стихии до первого компонента: He clocked 'im one right in the George (Он вмазал ему по физиономии). Буш стал президентом США в 2000 году, сменив на этом посту Билла Клинтона.

Первый (и пока единственный) афроамериканец на посту президента США, президент с фамилией африканского и средним именем арабского этимологического происхождения - Барак Хуссейн Обама II. Имя 44-го президента США и Лауреата Нобелевской премии мира 2009 года положено в основу многозначной рифмы Barack Obama = charmer: I tell you mate, he's a right Barack (Скажу тебе, приятель, он настоящий обаяшка (он неотразим). He's gorgeous! What an Obama! (Он великолепен! Какая прелесть!); Barack Obama = farmer: Bunch of Baracks taking to the streets again! (Сборище фермеров снова протестует на улицах!); Barack Obama = Pyjamas: She was wearing her Barack Obamas (На ней была пижама). Go put your Barackas, eh? (Иди, надень пижаму, а?). Рифма используется часто в сокращённой версии Barack.

В основу многозначной рифмы Donald Trump =1) dump и 2) hump положено имя 45-го президента США Дональда Трампа. Рифма соотносится с негативными референтами, что наглядно подтверждает тезис, что создатели рифмованного сленга не всегда благосклонно или почтительно обходятся с именами политиков, нередко рифмуя их с референтами, обозначающими в некоторых случаях нечто неприятное или неодобряемое обществом [8]. Рифма Donald Trump = dump, defecate позволяет деликатно избежать вульгарного или прямого обозначения дефекации: Oooh I could do with a Donald Trump right now. Второе значение рифмы сексуальное Donald Trump = hump (a sexual intercourse, a quickie): Had a Donald Trump in the back of the car. Относительно недавно рифма приобрела новое значение Donald Trump = hump, a bad mood, a fit of sulks (дурное настроение, тоска, депрессия): My girlfriend is starting to get the right Donald Trump. (У подруги портится настроение; начинается депрессия).

Рифма Donald Trump заслуживает социокультурного комментария. Вначале она была однозначной. Возникнув в 1990-х годах, рифма соотносилась со словом dump в значении an act of defecation. Дж. Грин отмечает, что в основу первоначальной рифмы легло имя Дональда Трампа, который в то время был известен как застройщик (property developer) [12, с. 81] и являлся одним из самых богатых людей в Америке [14, с. 1442]. Благодаря экстравагантному стилю жизни и откровенному стилю общения, а также благодаря своему успешному реалити-шоу «Кандидат», в котором он выступал как исполнительный продюсер и ведущий, Дональд Трамп стал знаменитостью. Вступив в борьбу за пост Президента США 16 июня 2015 года, Трамп неожиданно выиграл президентскую гонку у Хилари Клинтон и стал, таким образом, 45-м президентом США, войдя в историю как самый пожилой президент, и первый в истории США президент без опыта работы в правительстве или опыта военной службы. Также Дональд Трамп считается самым богатым американским Президентом за всю историю существования США. Его президентская кампания проходила под лозунгом "Make America Great Again” и получила беспрецедентное освещение в 
американских СМИ. Президентство Трампа отмечено скандалами. В декабре 2019 года Трамп стал третьим президентом в истории США, подвергшимся импичменту из-за серьёзных обвинений в злоупотреблении властью и препятствовании правосудию. Но импичмент не состоялся, так как противникам Трампа не удалось набрать две трети голосов. Более того, британская газета Financial Times включила его в список 50 человек, которые определили облик десятилетия. На момент написания данной статьи в США прошли президентские выборы, официальные итоги которых всё ещё не были объявлены спустя три недели, и Трамп долго не признавал своего поражения. 45-й президент США заявил, что проиграет на выборах только в случае нечестных действий со стороны демократов, его соперников. В случае победы на выборах Дональд Трамп пообещал избавиться от зависимости американской экономики от КНР. Тем не менее, фортуна отвернулась от Трампа. Новым президентом США избран представитель Демократической партии Джо Байден, который, таким образом, в возрасте 77 лет, стал старейшим в истории страны президентом на момент избрания.

Среди американских политиков конца XX - начала XXI века в рифмованном сленге зафиксированы также имена Роберта Макнамары, Кондолизы Райс, Джона Маккейна.

Рифма Macnamare = barrow (Glasgow Rh. Sl.) обыгрывает имя Роберта Стрэйнджа Макнамары (McNamara, Robert S.), американского политика-республиканца, который был министром обороны США в 1961- 1968 годах (при Джоне Кеннеди и Линдоне Джонсоне) [14, с. 815]. Он получил прозвище «Архитектор Вьетнамской войны», так как был её идеологом. Макнамара отвечал за применение системного анализа в государственной политике и, по сути, стоял у истоков дисциплины, которую сегодня называют «политическим анализом». С 1968 по 1981 годы Макнамара занимал пост президента Всемирного банка. В рифме, имеющей помету «характерна для Глазго», ощущается шотландское произношение: Macnamare = barrer (т. е. barrow).

Имя первой чернокожей женщины на посту госсекретаря США Кондолизы Райс отражает рифма Condoleezza Rice = price: Check the Condoleezza Rice on that item. (Проверить цену на этот товар). Кондолиза Райс сменила на этом посту Колина Пауэлла, в жилах которого течёт многонациональная кровь. Она стала второй женщиной в истории США (после Мадлен Олбрайт) на посту госсекретаря. Как и Колин Пауэлл, Кондолиза Райт была советником президента по национальной безопасности во время первого срока президентства Джорджа Буша. Кондолиза Райс в разной степени владеет русским, немецким, французским и испанским языками, профессионально играет на пианино; никогда не была замужем. Её считают одной из влиятельнейших женщинполитиков за всю историю США.

На имени американского политика и государственного деятеля Джона Сиднея Маккейна III основана рифма John McCane = insane (That bloke's gone John McCane). Он представлял Республиканскую партию и был сенатором США от штата Аризона с 1987 года до своей кончины в 2018 году. На выборах Президента США 2008 года Маккейн проиграл кандидату от Демократической партии Бараку Обаме. Джон Маккейн был известен своим резким отношением к российской внешней политике и критическим отношением к политике Президента России Владимира Путина. Маккейн считался одним из наиболее заметных «ястребов» в США. Его позиция по ряду знаковых вопросов внутренней политики (проблемы социального обеспечения, аборты, смертная казнь) носила отчётливо консервативный характер. Известно, что в последние годы своей жизни политик боролся с неизлечимым заболеванием, которое могло быть следствием пыток и избиений, которым он подвергался в лагере военнопленных, когда во время войны во Вьетнаме был сбит управляемый им самолет. Маккейн был освобождён из плена только 15 марта 1973 года, проведя более пяти лет в заключении. Освобождение стало возможным после подписания Парижских соглашений между США и ДРВ, согласно которым американские войска покидали Вьетнам. По ходу изложения заметим, что к слову insane в рифмованном сленге есть и другие рифмы, эксплуатирующие имена политиков мирового масштаба, например, Saddam Hussein = insane (You must be Saddam Hussein), которая первоначально рифмовалась со словом pain [12, с. 225].

Рифмованные единицы, созданные на основе прецедентных имён политиков и государственных деятелей, возникли относительно недавно. Например, в современном словаре рифмованного 
сленга [9] отсутствуют рифмы Abraham Lincoln = stinking; George Bush = mush; Barack Obama = 1) charmer; 2) farmer; 3) Pyjamas; Donald Trump = dump; Macnamare = barrow (barrer); Condoleezza Rice = price; John McCane = insane и зарегистрирована только одна - Eisenhower $=$ shower. В другом авторитетном словаре [12] из семи рассмотренных выше рифм мы находим только рифму Donald Trump $=$ dump.

Приведённый выше обзор показывает, что «засветившихся» в рифмованном сленге американских политиков не так много, зато намного больше имён американских знаменитостей из мира кино, поп-музыки и масс-культуры, причём ономастические рифмы с именами кино-идолов появились несколькими десятилетиями раньше. Приведём примеры в доказательство сделанного утверждения. Так, одна из первых рифм, основанная на имени голливудского киноактёра Эррола Флинна Errol Flynn = chin, датируется 1940-ми годами [12, с. 87]. Флинн играл авантюрных героев [14, с. 591]. Его собственная частная жизнь вызывала такое же пристальное внимание, как и его роли. Ряд громких скандалов в течение 1940-х годов испортили актёру его карьеру [7, с. 1056]. Имя американского киноактёра Грегори Пека, получившего Оскар за роль в фильме «Убить пересмешника», отражено в рифме Gregory Peck = 1) neck и 2) cheque и датируется 1950-ми годами [12, с. 107], австралийская рифма Betty Grable = a table датируется тем же периодом [12, с. 33] и эксплуатирует имя американской актрисы, певицы и танцовщицы, пик популярности которой пришёлся на период Второй мировой войны, когда Бетти Грейбл была признана американскими солдатами девушкой №1 с открытки [5, с. 245]. Новые рифмы, ещё не отражённые в словарях [9], [12], - Richard Gere = 1) queer (homosexual); 2) beer (I'm just going out for a couple of Richards) и Marilyn Monroes = toes. Первая рифма основана на имени Ричарда Тиффани Гира, популярного американского киноактёра, обладателя премии «Золотой глобус» и секс-символа 1980-х и 1990-х годов. Вторая рифма эксплуатирует имя американской киноактрисы, секс-символа 1950-х Мерилин Монро [14, с. 879], жизнь которой и её трагическая смерть стали публичным спектаклем.

В 1970-90-е годы к рифмам, основанным на именах Голливудских звёзд, добавились рифмы, эксплуатирующие имена кумиров поп-музыки, например, рифма Stevie Wonder =1) thunder [12, c. 241], которая приобрела новое значение 2) chunder (be sick: I can feel a Stevie coming on). Имя популярной американской поп-певицы Бритни Спирс, обладательницы премии «Грэмми», отражает многозначная рифма Britney Spears (чаще, Britneys) = beers [12, с. 43], а также 'ears' и 'tears' (Dry away those Britney Spears). Новая рифма Billy Ocean = sun tan lotion эксплуатирует сценическое имя англо-карибского музыканта Лесли Себастиана Чарльза, который является одним из наиболее характерных представителей поп-музыки 1980-х.

Завершая статью, отметим, что британским политикам в отношении рифмованного сленга повезло больше, чем их американским коллегам. Составитель словаря рифмованного сленга Дж. Грин даже составил небольшую шутливую подборку рифм, основанных на использовании имен парламентариев, которую он иронично озаглавил "Dishonorable Members": Douglas Hurd = turd/ third, enoch = towel, Harold Macmillan = villain, House of Lords $=$ cords, John Prescott $=$ waistcoat, John Selwyn $=$ bummer, Lord Sutch $=$ clutch $/$ crutch, Ted Heath $=$ thief/teeth, Tony Ben $=$ ten (pounds), Tony Blair = hair [12, c. 38]. Приведённый список далёк от завершения. Только за последние два десятилетия появились новые рифмы, эксплуатирующие имена нового поколения британских политиков. Социокультурный комментарий списка составил предмет отдельной статьи [8].

Подведём итоги. Мы рассмотрели образцы рифмованного сленга с ономастической основой, представленные именами политических и общественных деятелей современной Америки. К хорошо освоенным и привычным ономастическим рифмам, построенным на именах знаменитостей из мира кино, поп-музыки, массовой культуры и спорта, в последние десятилетия добавились рифмы, иллюстрирующие мир высокой политики.

Прецедентные имена, положенные в основу рифм, актуальны для сознания носителей англоговорящей культуры, входят в их картину мира и современную культурную коллективную память. В список зарифмованных президентов, получивших «прописку» в рифмованном сленге, вошли имена Авраама Линкольна, Дуайта Эйзенхауэра, Джорджа Буша, Барака Обамы и Дональда Трампа. Среди американских политиков конца XX - начала XXI века в рифмованном сленге за- 
фиксированы также имена Роберта Макнамары, Кондолизы Райс, Джона Маккейна. В контексте культурной грамотности [13] рифмованный сленг является показательным примером, дающим основания для выводов о значимости той или иной исторической личности в массовом обыденном сознании. В статье [8] мы дали анализ более 20 рифмам по заявленной теме против 8 рифм, представленных в данной статье. Наличие значительно большего количества рифм, эксплуатирующих имена британских политиков, по сравнению с именами американских, мы объясняем рядом причин: носители и пользователи британского рифмованного сленга хорошо знают своих политиков, сам рифмованный сленг зародился на Британских островах, а британский рифмованный сленг остаётся доминирующим среди социально-территориальных вариантов.

(C) Степанян К.А., Горшунов Ю.В., Горшунова Е.Ю., 2021

\section{Список литературы}

1. Горшунов Ю. В. Античные, библейские, мифологические и легендарные исторические личности и события в рифмованном сленге // Вестник Башкирского университета. 2017. Т. 22. №4. С.1047-1051.

2. Горшунов Ю. В. Герои и злодеи Второй мировой войны в компрометирующих контекстах английской идиоматики и рифмованного сленга // Тенденции развития науки и образования. № 61. Май 2020 (часть 8). С. 22-25.

3. Горшунов Ю. В. Достопримечательности Лондона в рифмованном сленге / Ю. В. Горшунов, Е. Ю. Горшунова // Вестник Башкирского университета. 2019. Т. 24. №1. С. 168-174.

4. Горшунов Ю. В. Кумиры спорта (теннис) в рифмованном сленге / Ю. В. Горшунов, Е. Ю. Горшунова // Моdern Humanities success. №2. 2018. С. 14-16.

5. Горшунов Ю. В. Эвфемизмы в рифмованном сленге: монография. Бирск: БФ БашГУ, 2016. 256 с. (на aнгл.) = Gorshunov, Yu. V. Euphemistic uses of Rhyming slang: monograph. Birsk, Bashkir State University at Birsk, 2016. 256 p.

6. Кто есть кто в мире / Гл. ред. Г. П. Шалаева. М.: СЛОВО, Эксмо, 2007. 1264 с.: ил.

7. Новый большой иллюстрированный энциклопедический словарь: М.: «Издательство «АСТ»: ООО «Издательство Астрель»: ИПЦ «Дизайн. Информация. Картография», 2004. LIII, [1256] с.: ил., карт.

8. Степанян К. А. Британские государственные, общественные и политические деятели конца XX - начала XXI века в рифмованном сленге [British state, public and political figures of the late 20th - early 21st century in rhyming slang] / К. А. Степанян, Ю. В. Горшунов, Е. Ю. Горшунова // Филологические науки в МГИМО: Журнал. № 3(23) 2020 / Гл. ред. В.А. Иовенко. - М.: МГИМОУниверситет, 2020. С. 42-47.

9. Ayto J. The Oxford Dictionary of Rhyming Slang. London, 2003. 309p.

10. Franklyn J. A Dictionary of Rhyming Slang. London: Routledge, 1994. 202p.

11. Green J. Cassell's Dictionary of Slang. WS Bookwell, 2003. 1326 p.

12. Green, Jonathon. The Big Book of Rhyming Slang. Cassell, 2002. 334 p.

13. Hirsh E. D. Jr. Cultural Literacy: What Every American Needs to Know. - Boston, 1987. 276 p.

14. Longman Dictionary of English Language and Culture. Longman, 1999. 1568 p.

15. Perkins, D. C. Cockney Rhyming Slang. A Domino Book, 2004. 48p.

\section{References}

1. Gorshunov, Yu. V. Antichnye, bibleiskie, mifologicheskie i legendarnye istoricheskie lichnosti i sobytiia v rifmovannom slenge [Biblical, mythological and legendary historical figures and events of the antique times in rhyming slang] // Vestnik Bashkirskogo universiteta. 2017. T. 22. №4. S.1047-1051.

2. Gorshunov, Yu. V. Geroi i zlodei Vtoroi mirovoi voiny v komprometiruiushchikh kontekstakh angliiskoi idiomatiki i rifmovannogo slenga [World War II heroes and villains in compromising contexts of English idioms and rhyming slang] // Tendentsii razvitiia nauki i obrazovaniia. № 61. Mai 2020 (chast' 8). S. 22-25.

3. Gorshunov, Yu. V. Dostoprimechatel'nosti Londona v rifmovannom slenge [London places of interest in rhyming slang] / Yu. V. Gorshunov, E. Yu. Gorshunova // Vestnik Bashkirskogo universiteta. 2019. T. 24. №1. S. 168-174.

4. Gorshunov, Yu. V. Kumiry sporta (tennis) v rifmovannom slenge [Sports idols (tennis) in rhyming slang] / Yu. V. Gorshunov, E. Yu. Gorshunova // Modern Humanities success. №2. 2018. C. 14-16.

5. Gorshunov, Yu. V. Evfemizmy v rifmovannom slenge: monografiia. [Euphemistic uses of Rhyming slang: monograph] Birsk: BF BashGU, 2016. 256 s. (na angl.)

6. Kto est' kto v mire [Who's Who in the World] / Gl. Red. G. P. Shalaeva. M.: SLOVO, Eksmo, 2007. 1264 s.: il.

7. Novyi bol'shoi illiustrirovannyi entsiklopedicheskii slovar' [New large illustrated encyclopedic dictionary]: M.: «Izdatel'stvo «AST»: OOO «Izdatel'stvo Astrel’»: IPTs «Dizain. Informatsiia. Kartografiia», 2004. LIII, [1256] c.: il., kart.

8. Stepanian, K. A. Britanskie gosudarstvennye, obshchestvennye I politicheskie deiateli kontsa XX - nachala XX1 veka v rifmovannom slenge [British state, public and political figures of the late XXth - early XX1st century in rhyming slang] / 
K. A. Stepanian, Yu. V. Gorshunov, E. Yu. Gorshunova // Filologicheskie nauki v MGIMO: Zhurnal. № 3(23) 2020 / Gl. Red. V.A. Iovenko. M.: MGIMO-Universitet, 2020. S. 42-47.

9. Ayto, J. The Oxford Dictionary of Rhyming Slang. London, 2003. 309p.

10. Franklyn, J. A Dictionary of Rhyming Slang. London: Routledge, 1994. 202p.

11. Green, J. Cassell's Dictionary of Slang. WS Bookwell, 2003. 1326 p.

12. Green, Jonathon. The Big Book of Rhyming Slang. Cassell, 2002. 334 p.

13. Hirsh, E. D. Jr. Cultural Literacy: What Every American Needs to Know. - Boston, 1987. 276 p.

14. Longman Dictionary of English Language and Culture. Longman, 1999. 1568 p.

15. Perkins, D. C. Cockney Rhyming Slang. A Domino Book, 2004. 48p.

\section{Сведения об авторах:}

Степанян Кристина Александровна - старший преподаватель кафедры английского языка №3 МГИМО (У) МИД России, (Россия, г. Москва). Сфера научных и профессиональных интересов: лингвистика, языкознание, обучение иностранным языкам, лингвокультурология, лингвострановедение, английский язык. E-mail: stepanyan.k@inno.mgimo.ru

Горшунов Юрий Владимирович - доктор филологических наук, профессор Башкирского государственного университета (Бирский филиал) (Россия, г. Бирск). Сфера научных и профессиональных интересов: общее и частное языкознание, социолингвистика, словообразование, лексикология, ономастика, фразеология, семантика, стилистика, прагматика, риторика, английский язык. E-mail: gorshunov_@rambler.ru

Горшунова Елизавета Юрьевна - кандидат филологических наук, доцент РАНХиГС (Россия, г. Москва), Сфера научных и профессиональных интересов: общее и частное языкознание, социолингвистика, словообразование, лексикология, ономастика, фразеология, семантика, стилистика, прагматика, риторика, английский язык. E-mail: ms.gorshunova@gmail.com

\section{About the authors:}

Kristina Stepanyan - Assistant Professor of MGIMO University Moscow, Spheres of research and professional interest: English teaching, cultural linguistics, E-mail: stepanyan.k@inno.mgimo.ru

Yurij Gorshunov - Doctor of Philology, professor of Bashkir State University at Birsk, (Russia, Birsk), Spheres of research and professional interest: English, teaching, cultural linguistics, E-mail: gorshunov_@rambler.ru

Elizaveta Gorshunova - PhD, Associate Professor of RANEPA Moscow, Spheres of research and professional interest: English, teaching, cultural linguistics, E-mail: ms.gorshunova@gmail.com 